\title{
Aldosterone receptor antagonists: current perspectives and therapies
}

REVIEW

This article was published in the following Dove Press journal:

Vascular Health and Risk Management

2I April 2013

Number of times this article has been viewed

\section{Jason L Guichard \\ Donald Clark III \\ David A Calhoun \\ Mustafa I Ahmed}

University of Alabama at Birmingham, Department of Medicine, Division of Cardiovascular Disease, Vascular Biology and Hypertension Program, Birmingham, AL, USA
Correspondence: Mustafa I Ahmed 1530 3rd Avenue South $\mathrm{CH}-19$, Suite 219, Birmingham, AL 35294-204I, USA

Tel + I 2059349632

Fax + I 2059757099

Email mahmed@uab.edu

\begin{abstract}
Aldosterone is a downstream effector of angiotensin II in the renin-angiotensinaldosterone system and binds to the mineralocorticoid receptor. The classical view of aldosterone primarily acting at the level of the kidneys to regulate plasma potassium and intravascular volume status is being supplemented by evidence of new "off-target" effects of aldosterone in other organ systems. The genomic effects of aldosterone are well known, but there is also evidence for non-genomic effects and these recently identified effects of aldosterone have required a revision in the traditional view of aldosterone's role in human health and disease. The aim of this article is to review the biological action of aldosterone and the mineralocorticoid receptor leading to subsequent physiologic and pathophysiologic effects involving the vasculature, central nervous system, heart, and kidneys. Furthermore, we outline current evidence evaluating the use of mineralocorticoid receptor antagonists in the treatment of primary aldosteronism, primary hypertension, resistant hypertension, obstructive sleep apnea, heart failure, and chronic kidney disease.
\end{abstract}

Keywords: aldosterone antagonist, mineralocorticoid receptor antagonist, primary aldosteronism, hypertension, obstructive sleep apnea, heart failure, chronic kidney disease

\section{Aldosterone, the mineralocorticoid receptor, and mineralocorticoid receptor antagonists}

The traditional view of aldosterone was that it acted primarily as a regulator of sodium, potassium, and water homeostasis. A new paradigm for aldosterone and its role in human health and disease is quickly emerging, however. ${ }^{1}$ Chronic exposure to elevated plasma aldosterone levels result in vascular, cardiac, renal, and metabolic complications that are independent of blood pressure (BP). Numerous cell culture, animal, and human studies have shown how aldosterone and the mineralocorticoid receptor (MR) are implicated in activation of a variety of pathologic processes including inflammation, remodeling, and fibrosis in several target organs. This article is an overview of the relevant past and recent findings regarding the interaction between aldosterone, the MR, and mineralocorticoid receptor antagonists (MRAs) in a variety of clinical conditions, including primary aldosteronism (PA), primary hypertension, resistant hypertension (RHTN), obstructive sleep apnea (OSA), heart failure (HF), and chronic kidney disease (CKD).

Aldosterone is a steroid hormone and downstream effector of angiotensin II in the renin-angiotensin-aldosterone system (RAAS). Aldosterone is mainly synthesized by the adrenal cortex, but is also present in vascular, brain, heart, and adipose tissues leading to local autocrine or paracrine effects. The MR has been identified 
in epithelial and non-epithelial tissues including the kidney, colon, vasculature, brain, heart, and adipose tissue and binds both mineralocorticoids and glucocorticoids with equal affinity. In addition to the well known effect of aldosterone in the kidney, including sodium reabsorption with concomitant potassium and hydrogen ion excretion, the more widespread effects of hyperaldosteronism include sympathetic nervous system activation, increased oxidant stress with inflammation, remodeling, apoptosis, and fibrosis (Figure 1). The biological action of the MR is mediated by the differential expression of proteins resulting from interactions of multiple elaborate transcriptional and translational mechanisms. ${ }^{2}$ Along with the well known genomic effects of aldosterone there is also evidence for non-genomic effects, whereby, rapid actions of aldosterone appear within several minutes in a target tissue. ${ }^{3}$

Aldosterone antagonists or MRAs have been proven to be beneficial for patients with a variety of clinical conditions including PA, primary and resistant hypertension, HF, and CKD. The three major MRA agents are spironolactone, eplerenone, and canrenone, each with different pharmacological characteristics as outlined in Table 1. Spironolactone is a nonselective, competitive MRA that is structurally similar to progesterone and metabolized in the liver to active metabolites. Additionally, spironolactone also acts as an antagonist to the androgen receptor, a weak antagonist to the glucocor- ticoid receptor, and agonist to the progesterone receptor. These receptor-mediated actions also result in the associated adverse effects of spironolactone including hyperkalemia, hyponatremia, gynecomastia, impotence, menstrual disturbances, hirsutism, and decreased libido. Canrenone is an active metabolite of spironolactone with a long half-life and is currently only available in Europe. Eplerenone is derived from spironolactone and considered a selective MRA with limited cross-reactivity for the androgen and progesterone receptors thus lacking many of the significant sexuallyrelated adverse effects known to be associated with the use of spironolactone.

Hyperkalemia is probably considered the most concerning adverse effect of MRA therapy with a rate in major clinical trials and in the community ranging from $2 \%-12 \% .^{4-6}$ The risk of serious hyperkalemia $(\mathrm{K}+\geq 6.0 \mathrm{mmol} / \mathrm{L})$ is minimized by routine plasma potassium and renal function monitoring and, if possible, avoidance of concurrent pharmacotherapies associated with hyperkalemia (eg, potassium supplements, other potassium-sparing diuretics, and nonsteroidal antiinflammatory drugs) and vigilant electrolyte surveillance if a patient is taking an angiotensin-converting-enzyme inhibitor (ACEI) or angiotensin II receptor blocker (ARB). ${ }^{7-9}$ Understandably, many practitioners caring for patients with renal dysfunction and an indication for MRA therapy may not prescribe a MRA due to the increased risk of developing

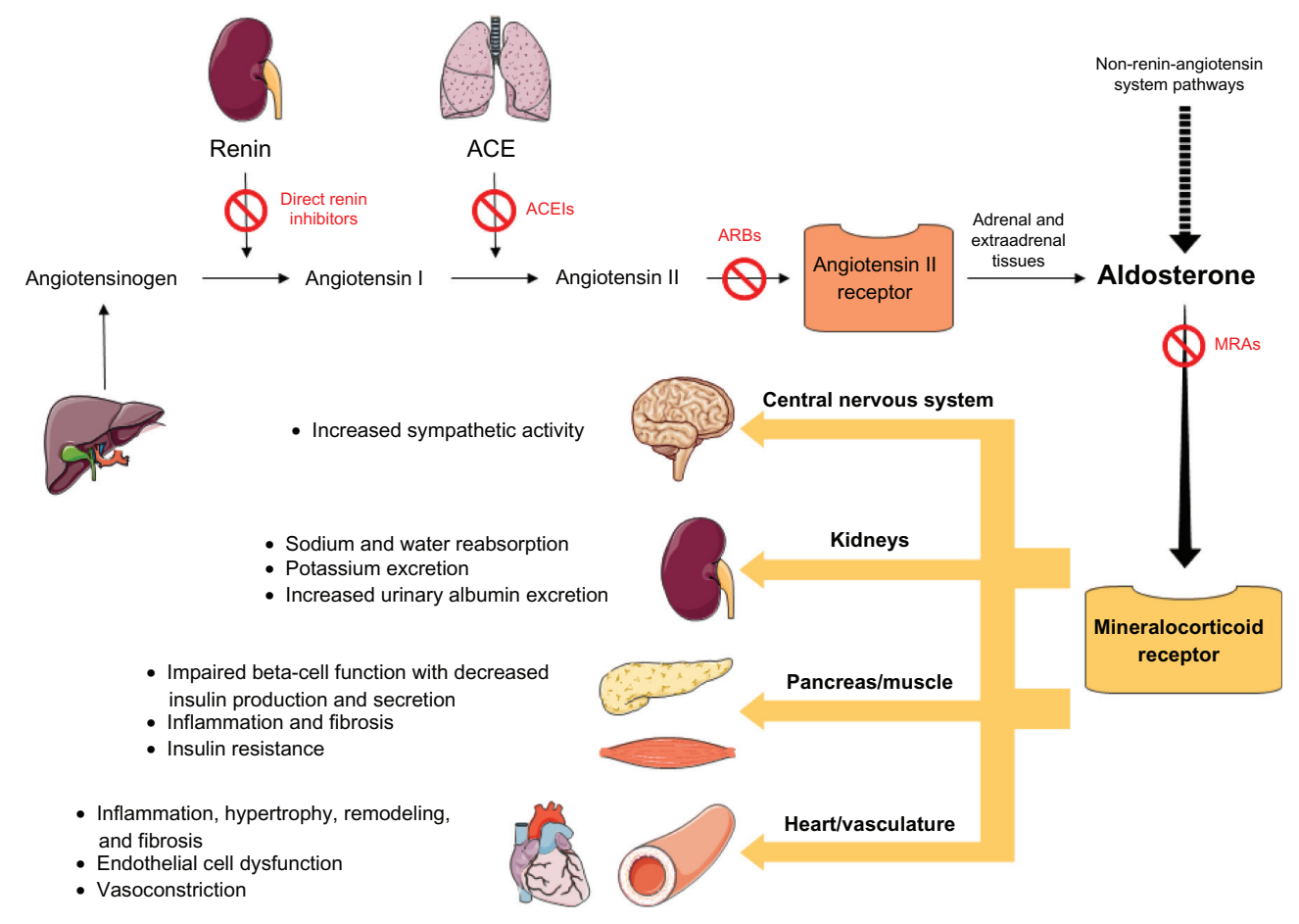

Figure I Activation of the mineralocorticoid receptor. 
Table I Pharmacological characteristics of spironolactone, canrenone, and eplerenone ${ }^{86-90}$

\begin{tabular}{|c|c|c|c|}
\hline Characteristics & Spironolactone & Canrenone & Eplerenone \\
\hline Molecular formula and mass, $\mathrm{g} / \mathrm{mol}$ & $\mathrm{C}_{24} \mathrm{H}_{32} \mathrm{O}_{4} \mathrm{~S}, 416.6$ & $\mathrm{C}_{22} \mathrm{H}_{28} \mathrm{O}_{3}, 340.5$ & $\mathrm{C}_{24} \mathrm{H}_{30} \mathrm{O}_{6}, 414.5$ \\
\hline Mean peak plasma concentration, $\mathrm{ng} / \mathrm{mL}$ & $80^{\mathrm{a}}$ & $|8|^{\mathrm{a}}$ & $1720^{\mathrm{b}}$ \\
\hline Time to peak plasma concentration, hours & $2.6^{\mathrm{a}}$ & $4.3^{\mathrm{a}}$ & $1.5^{\mathrm{b}}$ \\
\hline \multirow[t]{2}{*}{ Elimination half-life, hours } & I.3-2.0 (parent) & $18-22$ & $4-6$ \\
\hline & 13.8-16.5 (metabolites) & & \\
\hline Metabolism & Hepatic & Active metabolite & Hepatic (CYP3A4) \\
\hline Excretion & Urine (primarily), feces & Urine, feces & Urine $(67 \%)$, feces $(32 \%)$ \\
\hline Protein binding, \% & 90 & 98 & 50 \\
\hline Administration & Oral & Oral & Oral \\
\hline Clinical indications & $\begin{array}{l}\text { PA, edema (CHF, cirrhosis, or } \\
\text { nephrotic syndrome), primary } \\
\text { HTN, hypokalemia, and CHF } \\
\text { (NYHA class II-IV) }\end{array}$ & & $\begin{array}{l}\text { LVEF } \leq 40 \% \text { after } A M I \text { and } \\
\text { primary HTN }\end{array}$ \\
\hline Contraindications & $\begin{array}{l}\text { Anuria, AKI, significant impairment } \\
\text { of renal excretory function, or } \\
\text { hyperkalemia }\end{array}$ & & $\begin{array}{l}\text { Plasma } \mathrm{K}^{+}>5.5 \mathrm{mEq} / \mathrm{L} \text { at initiation, } \\
\mathrm{CrCl} \leq 30 \mathrm{~mL} / \mathrm{min} \text {, use with strong } \\
\mathrm{CYP} 3 \mathrm{~A} 4 \mathrm{inhibitors} \text {, plasma } \\
\mathrm{Cr}>2.0 \mathrm{mg} / \mathrm{dL} \text { in males } \\
\text { and }>1.8 \mathrm{mg} / \mathrm{dL} \text { in females, use } \\
\text { of } \mathrm{K}^{+} \text {supplements or } \mathrm{K}^{+} \text {-sparing } \\
\text { diuretics }\end{array}$ \\
\hline Common adverse effects & $\begin{array}{l}\text { Diarrhea, gynecomastia, sexual } \\
\text { dysfunction, menstrual irregularities, } \\
\text { hyperkalemia, metabolic acidosis, } \\
\text { and hyperuricemia }\end{array}$ & & $\begin{array}{l}\text { Hyperkalemia, increased } \mathrm{Cr} \text {, } \\
\text { diarrhea, hyponatremia, vaginal } \\
\text { bleeding, and hyperlipidemia }\end{array}$ \\
\hline Manufacturer & Generic & Generic & Generic \\
\hline
\end{tabular}

Notes: after administration of $100 \mathrm{mg}$ of spironolactone daily for 15 days, on the 15 th day, spironolactone was given immediately after a low-fat breakfast and blood was drawn thereafter; bafter oral administration of eplerenone at a dose of $100 \mathrm{mg}$ as an aqueous solution.

Abbreviations: PA, primary hyperaldosteronism; CHF, congestive heart failure; NYHA, New York Heart Association; HTN, hypertension; AKI, acute kidney injury; LVEF, left ventricular ejection fraction; AMI, acute myocardial infarction; $\mathrm{Cr}$, creatinine.

hyperkalemia. However, patients with CKD demonstrated a low incidence of hyperkalemia when using spironolactone. ${ }^{10}$ The importance of MRA therapy in patients with renal dysfunction was shown in a recent analysis from the RALES trial, which showed that although patients with $\mathrm{HF}$ and reduced estimated glomerular filtration rates had worse outcomes, they also received the greatest benefit from spironolactone therapy. ${ }^{11}$ Of particular interest, a novel therapeutic agent called RLY5016 (oral, a non-absorbed, potassium-binding polymer) prevented hyperkalemia in patients with HF receiving standard therapy and spironolactone. ${ }^{12}$ New potassium-binding agents, if shown to have long-term effectiveness and improve clinical outcomes, may have a role in safely starting and continuing MRA therapy in patients at high risk for developing hyperkalemia.

\section{Primary aldosteronism}

PA most commonly results from adrenal hyperplasia with other causes such as adrenal adenoma or other inherited disorders being less common. Some investigators require elevated plasma aldosterone levels (usually aldosterone $>15 \mathrm{ng} / \mathrm{dL}$ ) in addition to an elevated aldosterone to renin ratio for a positive screening test for PA, however, it has been reported that plasma aldosterone levels of 9-16 $\mathrm{ng} / \mathrm{dL}$ have been seen in patients diagnosed with PA by fludrocortisone suppression testing. ${ }^{13}$ The prevalence of PA in the general hypertensive population was evaluated in a study of 609 patients and found to be $6.1 \%$ with an average plasma aldosterone level of $9.67 \pm 6.93 \mathrm{ng} / \mathrm{dL} .{ }^{14}$ Interestingly, among those with stage III hypertension $(>180 / 110 \mathrm{mmHg})$ the prevalence of PA was $13.2 \%$ compared with $8 \%$ in those with stage II hypertension (160-179/100-109 mmHg) and 2\% in those with stage I hypertension (140-159/90-99 mmHg). ${ }^{14}$ In PA, left ventricular (LV) hypertrophy is associated with abnormal myocardial fibrosis leading to significant diastolic dysfunction. ${ }^{15,16}$ Compared with primary hypertension, patients with PA are at increased risk of cardiovascular events including coronary artery disease, myocardial infarction (MI), HF, stroke, and atrial fibrillation ${ }^{17-19}$ further demonstrating the adverse effects of excess aldosterone. It has been shown that in patients with PA, an appropriate surgical procedure or medical treatment with a MRA is associated with a significant reduction in cardiovascular events. ${ }^{18,20,21}$ 


\section{Primary hypertension}

Plasma aldosterone levels positively correlate with incident ${ }^{22,23}$ and resistant ${ }^{24,25}$ hypertension and MRA therapy has been utilized in the treatment of primary hypertension for many years. ${ }^{26}$ The pathology behind the increased plasma aldosterone and primary hypertension is likely due to increased vasoconstriction and endothelial cell dysfunction. In a randomized, double-blind, placebo-controlled trial evaluating the efficacy of eplerenone, 417 patients with mildto-moderate hypertension were randomized to eplerenone (50, 100, $400 \mathrm{mg}$ once daily or 25, 50, $200 \mathrm{mg}$ twice daily), spironolactone (50 mg twice daily), or placebo. The mean reductions from baseline to final visit seated systolic blood pressure (SBP) and diastolic blood pressure (DBP) were $\sim 15$ and $\sim 9 \mathrm{mmHg}$ respectively at the eplerenone $400 \mathrm{mg}$ daily total dosing ( $400 \mathrm{mg}$ once daily or $200 \mathrm{mg}$ twice daily) which was similar to the spironolactone $50 \mathrm{mg}$ twice daily dosing. ${ }^{27}$ Seated and 24-hour ambulatory BP was significantly reduced for all doses of eplerenone compared with placebo; the highest doses of eplerenone were comparable to the spironolactone group. ${ }^{27}$ In another randomized, double-blind trial using eplerenone and losartan in 348 African American and 203 white patients with mild-to-moderate hypertension and plasma aldosterone levels between $6.7-7.5 \mathrm{ng} / \mathrm{dL}$, eplerenone was as effective as losartan in reducing SBP and DBP in the high renin patient group, more effective than losartan in the low renin patient group, and more effective than losartan in African American patients. ${ }^{28}$ In a smaller study of 341 hypertensive patients, eplerenone was evaluated as add-on therapy in patients with inadequately controlled $\mathrm{BP}$ on an ACEI or ARB alone and showed that the addition of eplerenone over 8 weeks significantly lowered SBP in both groups and DBP in patients treated with an ARB. ${ }^{29}$ MRAs have been clearly shown to be effective in lowering $\mathrm{BP}$ in a wide-ranging patient population with primary hypertension.

In primary hypertension, activation of the RAAS correlates with LV hypertrophy and poor cardiovascular outcomes that may be attenuated with MRA therapy. In a small study of 11 patients with primary hypertension, spironolactone plus an ACEI (trandolapril) versus an ACEI alone decreased LV mass in correlation with reduction in plasma procollagen type III amino-terminal peptide (PIIINP) levels and suggests that MR blockade limits extracellular collagen turnover. ${ }^{30}$ The 4-E Left Ventricular Hypertrophy Study (Effects of eplerenone, enalapril, and eplerenone/enalapril in patients with essential hypertension and left ventricular hypertrophy) was a 9-month, randomized, double-blind trial comparing LV hypertrophy regression assessed by MRI in 202 patients with hypertension and LV hypertrophy treated with eplerenone $200 \mathrm{mg}$ daily, enalapril $40 \mathrm{mg}$ daily, or eplerenone $200 \mathrm{mg}$ and enalapril $10 \mathrm{mg}$ daily. ${ }^{31}$ This study showed that eplerenone was as effective as enalapril in LV hypertrophy regression and BP control and combination therapy was more effective in reducing LV hypertrophy and SBP than eplerenone alone. ${ }^{31}$ Additionally, a small, randomized, double-blind study of 16 hypertensive patients showed that eplerenone treatment was associated with reduced stiffness, decreased collagen-elastin ratio, and a reduction in circulating inflammatory mediators after 1 year when compared to atenolol..$^{32}$ Taken together, these studies suggest that in hypertensive patients, MRA therapy not only lowers BP but may also reduce LV hypertrophy and limit end organ damage.

Increased sympathetic nerve activity has been demonstrated in patients with primary hypertension, RHTN, and HF which contributes to the cardiovascular morbidity and mortality observed in these patient populations. ${ }^{33}$ Recently, it has been shown that in patients with aldosterone-producing adenomas there is reversible increased sympathetic nerve activity after unilateral adrenalectomy as well as plasma aldosterone and BP declines. ${ }^{34}$ Due to the hypothesis that increased sympathetic nerve activity may contribute to the morbidity and mortality related to longstanding uncontrolled hypertension, device-based therapies including baroreflex activation therapy and renal denervation are being studied in patients with primary and resistant hypertension. Devicebased therapies, although promising and shown to lower sympathetic nerve activity in hypertensive patients, have not yet demonstrated improved long-term cardiovascular outcomes. Recently, Raheja et al has shown that spironolactone $(25 \mathrm{mg} /$ day $)$ attenuates both chlorthalidone-induced sympathetic activation and insulin resistance in humans that was independent of BP reduction. ${ }^{35}$ This study by Raheja et al demonstrates that MR antagonism in the central nervous system and decreasing sympathetic activity are important therapeutic targets. These studies provide more evidence for the continued development of new pharmacologic and device-based therapies as sympatholytic agents for hypertension. ${ }^{35}$

\section{Resistant hypertension and obstructive sleep apnea}

The 2008 Scientific statement from the American Heart Association defined RHTN as BP remaining above goal $(<140 / 90 \mathrm{mmHg}$ for the general population and $<130 / 80 \mathrm{mmHg}$ for patients with diabetes or 
renal disease), despite the concurrent use of optimal doses of three antihypertensive agents of different classes, ideally including a diuretic. ${ }^{36}$ Poor cardiovascular outcomes are believed to be increased in patients with RHTN due to longstanding, severe hypertension complicated by additional risk factors including obesity, diabetes, and renal dysfunction. In a recently published study, among stable hypertensive patients with atherothrombotic disease in the international Reduction of Atherothrombosis for Continued Health (REACH) registry, the prevalence of RHTN was $12.7 \%$ and identified a subgroup with significantly increased rates of cardiovascular death, MI, or stroke through 4 years of follow-up (HR: 1.11 [95\% CI: $1.02-1.20] ; P=0.017) .{ }^{37}$

Secondary forms of hypertension are common in patients with RHTN, of which PA is the most common and considered to be a significant contributor to treatment resistance. It is generally believed that $\sim 10 \%$ of hypertensive patients may have biochemical evidence for PA and are more likely to have RHTN. Among patients with RHTN the prevalence of PA is $17 \%$ to $22 \%{ }^{24,38-40}$ which is considerably higher than hypertensive patients without treatment resistance. A prospective analysis evaluating 279 patients with RHTN, and 53 control patients with normal BP or hypertension controlled with $\leq 2$ antihypertensive medications, showed significantly higher levels of plasma aldosterone (13.0 \pm 0.5 versus $8.4 \pm 0.7 \mathrm{ng} / \mathrm{dL}$ ), aldosterone-renin ratio, 24-hour urinary aldosterone, and brain and atrial natriuretic peptide levels, and significantly lower levels of plasma renin activity in patients with RHTN versus control patients. ${ }^{41}$ This finding indicates increased intravascular volume in patients with RHTN despite treatment with the recommended doses of thiazide diuretics. Additionally, in a prospective clinical trial by Gaddam et al, 108 patients were evaluated for the effect of spironolactone in RHTN patients with $(n=37)$ and without $(n=71)$ hyperaldosteronism. ${ }^{42}$ Spironolactone treatment in both the hyperaldosteronism and normal aldosterone groups was associated with significantly decreased SBP and LV mass at the 3-month follow-up. ${ }^{42}$ In the hyperaldosteronism group there was also significant decrease in left atrial volume, RV and LV end-diastolic volumes, and brain natriuretic peptide. ${ }^{42}$ These studies support the hypothesis that hyperaldosteronism causes intravascular volume overload in patients with RHTN and the benefit of MRA therapy in patients with RHTN appears to be independent of underlying plasma aldosterone levels.

Spironolactone effectively reduces SBP and DBP as add-on therapy to a current antihypertensive regimen in patients with RHTN. ${ }^{43,44}$ In a recent open-label prospective study, 175 patients with RHTN received spironolactone in doses of 25 to $100 \mathrm{mg} /$ day and after a median interval of 7 months, the mean 24-hour ambulatory SBP and DBP were reduced by $16 \mathrm{mmHg}$ and $9 \mathrm{mmHg}$, respectively, reductions that persisted at a median of 15 months follow-up. ${ }^{45}$ Another open-label prospective crossover study comparing spironolactone (25-50 mg/day) added to an ACEI or ARB vs the combination of an ACEI and ARB in 42 patients with RHTN, demonstrated that the addition of spironolactone significantly reduced BP compared with dual blockade of the RAAS alone (24-hour mean BP reduction 21/9 mmHg vs $7 / 3 \mathrm{mmHg}$, respectively). ${ }^{46} \mathrm{BP}$ control was achieved by $21 \%$ of patients on dual blockade and up to $56 \%$ on spironolactone with ambulatory BP monitoring. ${ }^{46}$ These studies strongly support the addition of MRA therapy to standard therapy in patients with RHTN not controlled on three medications.

Sleep disordered breathing and obstructive sleep apnea (OSA) are associated with hypertension ${ }^{47}$ and appear to be especially pronounced in patients with RHTN. ${ }^{48}$ Furthermore, there is a documented association between excess plasma aldosterone levels (16.3 $\pm 8.1 \mathrm{ng} / \mathrm{dL})$, RHTN, and worsened severity of OSA. ${ }^{25,49}$ Gaddam et al tested the hypothesis that aldosterone-mediated chronic fluid retention influences the severity of OSA in patients with RHTN in an open-label study after spironolactone (25-50 mg/day) was added to existing antihypertensive therapy for 8 weeks. ${ }^{50}$ The apnea-hypopnea index $(39.8 \pm 19.5$ vs $22.0 \pm 6.8$ events/hour; $P<0.05)$, hypoxic index $(13.6 \pm 10.8$ versus $6.7 \pm 6.6$ events/hour; $P<0.05$ ), weight, and clinic and ambulatory BPs were significantly reduced, which supports the hypothesis that MRA therapy reduces the severity of OSA in patients with RHTN. $^{50}$ The interesting interplay between hyperaldosteronism, RHTN, and OSA remains an area of ongoing study and the increased plasma aldosterone in RHTN and OSA is the likely culprit of increased fluid retention and vascular resistance.

\section{Heart failure \\ Heart failure with reduced ejection fraction (HFrEF) or systolic HF}

In patients with HF, plasma aldosterone may reach levels $(\sim 300 \mathrm{ng} / \mathrm{dL})$ many fold higher than those measured in normal subjects $(5-15 \mathrm{ng} / \mathrm{dL}) .{ }^{51}$ Nearly a third of patients with LV systolic dysfunction have elevated plasma aldosterone levels above the upper limit of normal $(>15.0 \mathrm{ng} / \mathrm{dL})$ despite evidence of ACE inhibition. ${ }^{52,53}$ Aldosterone production eludes the effects of ACEIs and ARBs after chronic treatment in patients with HF, returning to or above initial 
baseline in a phenomenon termed aldosterone "escape" or "breakthrough." 52 This phenomenon may explain the beneficial effects of MRA therapy when added to an ACEI or ARB in patients with HF.

The Randomized Aldactone Evaluation Study (RALES) published in 1999 was the first large randomized, doubleblind, placebo-controlled trial to evaluate the effect of a MRA on survival in 1663 patients (822 to spironolactone and 841 to placebo) with current New York Heart Association (NYHA) class III-IV symptoms or history of NYHA class IV symptoms due to LV dysfunction (LV ejection fraction $(\mathrm{EF}) \leq 35 \%$ ) on optimal medical therapy. ${ }^{54}$ Patients were randomized to spironolactone $(25-50 \mathrm{mg} /$ day, mean daily study dose was $26 \mathrm{mg}$ ) for a mean follow-up of 24 months. ${ }^{54}$ Notably, the trial was terminated early due to a significant mortality benefit in the spironolactone group. Primary outcome was all-cause mortality and was 35\% in the spironolactone group vs $46 \%$ in the placebo group (RR: 0.70 [95\% CI: 0.60-0.82]; $P<0.001)$ with a number needed to treat (NNT) of 9 over 24 months of therapy. ${ }^{54}$ Secondary end points included death from cardiac causes, hospitalization for cardiac causes, the combined incidence of death from cardiac causes or hospitalization for cardiac causes, and a change in the NYHA class which were also reduced or improved in the spironolactone group. ${ }^{54}$ In addition to being the first trial to show a mortality benefit with spironolactone in patients with HF, additional insights from RALES suggest that spironolactone limited the excessive extracellular matrix turnover in the heart which may contribute to prevention of adverse cardiac remodeling in patients with $\mathrm{HF}^{55}$

The Eplerenone Post-Acute Myocardial Infarction Heart Failure Efficacy and Survival Study (EPHESUS) was an international, randomized, double-blind, placebo-controlled trial published in 2003 evaluating the effect of eplerenone in 6642 patients (3313 to eplerenone and 3319 to placebo) with LV dysfunction (LVEF < 40\%) after acute MI. ${ }^{56}$ Eplerenone was administered at $25-50 \mathrm{mg} /$ day (mean final daily study dose was $43 \mathrm{mg}$ ) between 3 and 14 days after acute MI with a mean follow-up of 16 months. ${ }^{56}$ The two primary end points were time to death from any cause and time to death from cardiovascular causes or first hospitalization for a cardiovascular event. All-cause mortality was $14.4 \%$ in the eplerenone group vs $16.7 \%$ in the placebo group (RR: 0.85 [95\% CI: $0.75-0.96] ; P=0.008$ ) with an NNT of 43 over 16 months of therapy. ${ }^{56}$ Death from cardiovascular causes or first hospitalization for a cardiovascular event was $26.7 \%$ in the eplerenone group versus $30.0 \%$ in the placebo group (RR: 0.87 [95\% CI: $0.79-0.95$ ]; $P=0.002$ ) with an NNT of 30, over 16 months of therapy. ${ }^{56}$ The major secondary end points were death from cardiovascular causes and death from any cause or any hospitalization which were also reduced in the eplerenone group. ${ }^{56}$ In a similar study evaluating MRA therapy on post-infarction LV remodeling, Hayashi et al evaluated spironolactone and ACEI $(n=65)$ or ACEI alone $(n=69)$ in 134 patients with first acute anterior $\mathrm{MI}$ after revascularization and found that spironolactone and ACEI prevented post-infarction LV remodeling better than ACEI alone. ${ }^{57}$ In both RALES and EPHESUS the plasma aldosterone levels were normal, suggesting that MR activation occurs by ligands other than aldosterone, thus providing strong evidence for the therapeutic effectiveness of MRA therapy despite normal aldosterone levels in patients with HF.

The Eplerenone in Mild Patients Hospitalization And Survival Study in Heart Failure (EMPHASIS-HF) was a randomized, double-blind, placebo-controlled trial published in 2011 evaluating eplerenone in patients with LV dysfunction and NYHA class II symptoms on optimal medical therapy. ${ }^{58}$ Eplerenone was used at a dose of $25-50 \mathrm{mg} /$ day (mean daily study dose was $39.1 \mathrm{mg}$ at 5 months) in addition to standard therapy. ${ }^{58}$ The trial enrolled 2737 patients with NYHA class II symptoms and LVEF $\leq 30 \%$ (patients with $\mathrm{LVEF}>30 \%$ but $<35 \%$ could be included if QRS complex was $>130 \mathrm{msec}$ on ECG). ${ }^{58}$ The primary outcome was a composite of death from cardiovascular causes or a first hospitalization for HF and was $18.3 \%$ in the eplerenone group and $25.9 \%$ in the placebo group (HR: 0.63 [95\% CI: 0.54-0.74]; $P<0.001) .{ }^{58}$ The trial was terminated early due to the benefit of eplerenone with a median follow-up of 21 months. Post hoc analyses of the EMPHASIS-HF trial have suggested that patients with mild HF and treated with eplerenone had significantly fewer HF hospitalizations especially within the first year. ${ }^{59}$

Canrenone has been shown to improve diastolic function in patients with primary hypertension independent of effects on BP and LV mass regression suggesting a direct myocardial effect. ${ }^{60}$ There are less clinical data on canrenone than for other MRAs, but recently, the randomized, double-blind, placebo-controlled AREA IN-CHF (Anti-remodeling Effect of Canrenone in Patients with Mild Chronic Heart Failure) trial evaluated LV remodeling and the composite endpoint of cardiac death and hospitalization using canrenone on top of optimal medical treatment $(25 \mathrm{mg} /$ day titrated up to $50 \mathrm{mg} /$ day, mean dose was $43.8 \mathrm{mg}$ /day) for 12 months in patients with NYHA class II HF. ${ }^{61}$ The trial showed a significant reduction in the composite endpoint of cardiac 
death and hospitalization in the canrenone vs placebo group (7.9\% vs $15.1 \%, P=0.02$ ) with a mild improvement of LVEF in the canrenone group. ${ }^{61}$

An ongoing multicenter, randomized, open-labeled study called the Aldosterone Blockade Early After Acute Myocardial Infarction (ALBATROSS, ClinicalTrials.gov Identifier: NCT01059136) trial is designed to evaluate MR blockade early after acute $\mathrm{MI}$ in addition to standard therapy. ${ }^{62}$ This study will assess the effectiveness of aldosterone blockade by a $200 \mathrm{mg}$ intravenous bolus of potassium canrenoate followed by a daily $25 \mathrm{mg}$ dose of spironolactone for 6 months, on top of standard therapy compared with standard therapy alone among 1600 patients admitted for ST-segment elevation MI (STEMI) or high-risk (Thrombolysis In Myocardial Infarction [TIMI] Score $\geq 3$ ) non-ST-segment elevation MI (NSTEMI) within 72 hours after symptom onset. ${ }^{62}$ The primary outcome is 6-month rate of the composite of death, resuscitated cardiac arrest, potentially lethal ventricular arrhythmia, indication for implantable cardioversion device, and occurrence or aggravation of HF. ${ }^{62}$ This study is expected to reach completion in February 2013. The results of this study are heavily anticipated as will be shown, in contrast to previous studies studying the chronic effects of MRAs, the acute effect of MRA therapy after a STEMI or high-risk NSTEMI.

These clinical trials confirm the involvement of MR activation in systolic HF, independent of changes in plasma aldosterone and potassium levels, indicating that the beneficial effects of MRAs go beyond their diuretic or potassiumsparing properties. ${ }^{63}$ Currently available evidence supports the overall view that MRA therapy is cardioprotective in patients with systolic HF. Unfortunately, despite the well documented benefits of MRAs in systolic HF, clinical use remains far below expectations and they are grossly underused in community practices despite detailed guidelines about proper patient selection. ${ }^{64-66}$ Studies suggest that of the patients who are eligible for MRA therapy only 33\%-36\% receive therapy. ${ }^{6,67}$ Enhanced practitioner education and focused, performance-improvement interventions may be effective measures to expand the use of MRAs, although initiation of MRA therapy should be done carefully and selectively in appropriate patients. ${ }^{68}$

\section{Heart failure with preserved ejection fraction (HFpEF) or diastolic HF}

Heart failure with preserved ejection fraction (HFpEF) is an increasing public health concern. HFpEF is the clinical syndrome of HF, but with preserved systolic function and abnormalities in diastolic function involving LV relaxation and stiffness. Myocardial fibrosis is a key pathological feature of HFpEF and is a major determinant of myocardial stiffness and diastolic dysfunction. Aldosterone is a potent stimulator of myocardial and vascular fibrosis, thus activation of the MR may be a key mediator in the pathologic progression of $\mathrm{HFpEF}$ and an important therapeutic target. Inappropriate activation of the RAAS has been shown to lead to the development of HFpEF via different mechanisms, including increased oxidative stress, inflammation, hypertrophy, and fibrosis. ${ }^{69}$ By reducing cardiac fibrosis and improving function, MRA therapy has the potential to be beneficial in HFpEF.

In a randomized, double-blinded, placebo-controlled study of 30 hypertensive patients with HFpEF, spironolactone therapy ( $25 \mathrm{mg}$ /day) over 6 months improved LV relaxation and filling patterns independent of changes in BP when compared with placebo. ${ }^{70}$ More recent studies provide additional evidence suggesting a possible benefit of MRA therapy in the management of patients with HFpEF. Mak et al and Edwards et al demonstrated that MRA therapy prevented a progressive increase in markers of collagen turnover and improved diastolic function in patients with HFpEF. ${ }^{71,72} \mathrm{~A}$ randomized, double-blind, placebo-controlled trial of 44 patients with HFpEF evaluated eplerenone treatment using a primary end point of 6-minute walk distance and secondary end points of diastolic function and biomarkers of collagen turnover. ${ }^{73}$ At 6 months there were similar improvements in 6-minute walk distance between the eplerenone and placebo groups, although eplerenone was associated with a significant reduction in plasma markers of collagen turnover and improvement in echocardiographic measures of diastolic function. ${ }^{73}$ Most recently, the Aldosterone Receptor Blockade in Diastolic Heart Failure (Aldo-DHF) trial was designed to test the hypothesis that MR antagonism with spironolactone would improve diastolic function and maximal exercise capacity in patients with HFpEF. ${ }^{74}$ The Aldo-DHF trial was a multicenter, randomized, double-blind, placebo-controlled trial of 422 patients with chronic NYHA class II or III symptoms, preserved LVEF of $\geq 50 \%$, and echocardiographic evidence of diastolic dysfunction, who were randomly assigned to spironolactone $25 \mathrm{mg}$ once daily $(\mathrm{n}=213)$ or placebo $(\mathrm{n}=209) .{ }^{74} \mathrm{Co}-$ primary endpoints were changes in diastolic function $\left(\mathrm{E} / \mathrm{e}^{\prime}\right)$ on echocardiography and maximal exercise capacity (peak $\mathrm{VO}_{2}$ ) on cardiopulmonary exercise testing at 12 months. MR antagonism improved diastolic function (E/e' decreased from $12.7[ \pm 3.6]$ to $12.1[ \pm 3.7]$ with spironolactone and increased from $12.8[ \pm 4.4]$ to $13.6[ \pm 4.3]$ with placebo [adjusted mean 
difference, $-1.5 ; 95 \% \mathrm{CI},-2.0$ to $-0.9 ; P<0.001])$ but did not affect maximal exercise capacity, patient symptoms, or validated measures of quality of life. ${ }^{74}$ The Aldo-DHF trial showed that MRAs may improve diastolic function by echocardiography, but did not show any improvement in the measured clinical factors. Additional studies are needed to assess whether bettering diastolic function improves clinical endpoints. Still to be completed is the Trial of Aldosterone Antagonist Therapy in Adults with Preserved Ejection Fraction Congestive Heart Failure (TOPCAT, ClinicalTrials.gov Identifier: NCT00094302), which is an ongoing randomized, double-blinded, placebo-controlled trial of spironolactone (15-45 mg/day or placebo) in up to $3515 \mathrm{HFpEF}$ patients with targeted mean follow-up of 3.75 years and minimum follow-up of 15 months for the final randomized patient. ${ }^{75}$ The primary end point is the composite of cardiovascular death, hospitalization for HF, or aborted cardiac arrest with secondary end points including quality of life, nonfatal cardiovascular events, and new-onset atrial fibrillation. ${ }^{75}$ This large, randomized controlled trial is expected to reach completion in April 2013 and could potentially demonstrate MRA therapy as an important evidence-based therapeutic for improving morbidity and mortality in patients with HFpEF.

\section{Chronic kidney disease}

PA is associated with renal injury and the development of $\mathrm{CKD}{ }^{76}$ The major therapeutic intervention to delay the progression of CKD involves the use of ACEIs, ARBs and, recently, direct renin inhibitors. However, even at full doses, ACEIs and/or ARBs decrease but do not prevent the progression of CKD. MRA therapy is an emerging strategy for delaying the progression of $\mathrm{CKD}$ through additional inhibition of the RAAS. ${ }^{77,78}$ MRA therapy has been shown to be highly effective in reducing renal injury and albuminuria and several clinical studies have assessed the effects of an add-on MRA to ACEI and/or ARB in patients with CKD. In a unique study involving 269 older patients ( $\geq 50$ years of age) with hypertension and widened pulse pressure, eplerenone and amlodipine had similar SBP and pulse pressure lowering effects, but eplerenone reduced microalbuminuria to a greater extent than amlodipine. ${ }^{79}$ A multicenter, randomized, open-labeled trial examined the effectiveness of RAAS blockade via three different mechanisms ("triple blockade") by adding an MRA to the treatment of patients who did not respond adequately to the dual blockade with an ACEI and ARB. ${ }^{80}$ In this study, 32 patients with proteinuria $(>0.5 \mathrm{~g} /$ day) were enrolled after more than 12 weeks of ACEI (enalapril $5 \mathrm{mg} /$ day) and ARB (losartan $50 \mathrm{mg} /$ day) combination treatment, after which, the patients were given either triple blockade with spironolactone ( $25 \mathrm{mg}$ /day) or control (trichlormethiazide $1 \mathrm{mg}$ or furosemide $20 \mathrm{mg}$ ) and after 1 year the urinary protein level decreased by $58 \%(P<0.05)$ with the triple blockade but was unchanged in the controls. ${ }^{80}$ In a recent systematic review and meta-analysis including 11 trials (991 patients) of patients with CKD, it was found that adding an MRA to an ACEI and/or ARB significantly reduced proteinuria more than therapy with a single agent alone. ${ }^{81}$ Most recently, a randomized, double-blind, placebo-controlled crossover trial in 21 patients with type 1 diabetes and persistent microalbuminuria used spironolactone ( $25 \mathrm{mg} /$ day) or placebo for 60 days in addition to standard therapy and showed that spironolactone decreased the primary endpoint of urinary albumin excretion from $90 \mathrm{mg} /$ day to $35 \mathrm{mg} /$ day $(P=0.01)$, and the improvement was independent of BP. ${ }^{82}$ The results of these recent clinical trials show that low dose MRA therapy has the potential to become part of standard therapy for patients with $\mathrm{CKD}$, although clinical trials assessing harder clinical end points are required.

MRA therapy has been limited by widespread concern about hyperkalemia, even though it has been recently shown that spironolactone administration in mild to moderate CKD patients resulted in a $<1 \%$ incidence of serious hyperkalemia $\left(\mathrm{K}^{+} \geq 6.0 \mathrm{mmol} / \mathrm{L}\right) .{ }^{83} \mathrm{In}$ a recent review, Shavit et al demonstrate that the increased risk of hyperkalemia in MRA treated patients has been exaggerated and the risk for developing hyperkalemia in both CKD and end-stage renal disease patients is significantly less than previously thought. ${ }^{84}$ Like with all treatment plans, the risk-benefit ratio should be considered along with careful laboratory monitoring for all patients with renal disease on MRA therapy.

\section{Conclusion}

Aldosterone is a complex steroid hormone with widespread physiologic effects. Chronically elevated levels of aldosterone are more common than traditionally thought, and contribute significantly to a variety of disease processes. The pathologic role of excess aldosterone is supported by a growing body of literature demonstrating therapeutic benefit of MR blockade in multiple conditions including primary hypertension, RHTN, congestive HF, and CKD. Hyperaldosteronism also appears to play a role in OSA and the relationship between these two important conditions remains an area of ongoing study. Thirdand fourth-generation MRAs are in preclinical development and may offer novel alternatives with better tissue selectivity than currently approved therapies. ${ }^{85}$ Further advances in our 
understanding of aldosterone and the role of MRAs in associated conditions will serve to continue to improve clinical outcomes.

\section{Disclosure}

The authors have no conflicts of interest to declare in this work.

\section{References}

1. Funder JW. Minireview: aldosterone and mineralocorticoid receptors: past, present, and future. Endocrinology. 2010;151(11):5098-5102.

2. Viengchareun S, Le Menuet D, Martinerie L, et al. The mineralocorticoid receptor: insights into its molecular and (patho)physiological biology. Nucl Recept Signal. 2007;5:e012.

3. Funder JW. Minireview: aldosterone and the cardiovascular system: genomic and nongenomic effects. Endocrinology. 2006;147(12):5564-5567.

4. Juurlink DN, Mamdani MM, Lee DS, et al. Rates of hyperkalemia after publication of the Randomized Aldactone Evaluation Study. $N$ Engl $J$ Med. 2004;351(6):543-551.

5. Witham MD, Gillespie ND, Struthers AD. Hyperkalemia after the publication of RALES. $N$ Engl J Med. 2004;351(23):2448-2450; author reply 2448-2450.

6. Zannad F, Gattis Stough W, Rossignol P, et al. Mineralocorticoid receptor antagonists for heart failure with reduced ejection fraction: integrating evidence into clinical practice. Eur Heart J. 2012;33(22):2782-2795.

7. Shah KB, Rao K, Sawyer R, Gottlieb SS. The adequacy of laboratory monitoring in patients treated with spironolactone for congestive heart failure. J Am Coll Cardiol. 2005;46(5):845-849.

8. Pitt B, Bakris G, Ruilope LM, DiCarlo L, Mukherjee R; EPHESUS Investigators. Serum potassium and clinical outcomes in the Eplerenone Post-Acute Myocardial Infarction Heart Failure Efficacy and Survival Study (EPHESUS). Circulation. 2008;118(16):1643-1650.

9. Jessup M, Abraham WT, Casey DE, et al. 2009 focused update: ACCF/ AHA Guidelines for the Diagnosis and Management of Heart Failure in Adults: a report of the American College of Cardiology Foundation/ American Heart Association Task Force on Practice Guidelines: developed in collaboration with the International Society for Heart and Lung Transplantation. Circulation. 2009;119(14):1977-2016.

10. Pisoni R, Acelajado MC, Cartmill FR, et al. Long-term effects of aldosterone blockade in resistant hypertension associated with chronic kidney disease. J Hum Hypertens. 2012;26(8):502-506.

11. Vardeny $\mathrm{O}, \mathrm{Wu} \mathrm{DH}$, Desai A, et al. Influence of Baseline and Worsening Renal Function on Efficacy of Spironolactone in Patients With Severe Heart Failure: Insights From RALES (Randomized Aldactone Evaluation Study). J Am Coll Cardiol. 2012;60(20):2082-2089.

12. Pitt B, Anker SD, Bushinsky DA, et al. Evaluation of the efficacy and safety of RLY5016, a polymeric potassium binder, in a double-blind, placebo-controlled study in patients with chronic heart failure (the PEARL-HF) trial. Eur Heart J. 2011;32(7):820-828.

13. Funder JW, Carey RM, Fardella C, et al. Case detection, diagnosis, and treatment of patients with primary aldosteronism: an endocrine society clinical practice guideline. J Clin Endocrinol Metab. 2008;93(9):3266-3281.

14. Mosso L, Carvajal C, Gonzalez A, et al. Primary aldosteronism and hypertensive disease. Hypertension. 2003;42(2):161-165.

15. Rossi GP, Di Bello V, Ganzaroli C, et al. Excess aldosterone is associated with alterations of myocardial texture in primary aldosteronism. Hypertension. 2002;40(1):23-27.

16. Muiesan ML, Salvetti M, Paini A, et al. Inappropriate left ventricular mass in patients with primary aldosteronism. Hypertension. 2008;52(3): 529-534.

17. Milliez P, Girerd X, Plouin PF, Blacher J, Safar ME, Mourad JJ. Evidence for an increased rate of cardiovascular events in patients with primary aldosteronism. J Am Coll Cardiol. 19, 2005;45(8):1243-1248.
18. Catena C, Colussi G, Nadalini E, et al. Cardiovascular outcomes in patients with primary aldosteronism after treatment. Arch Intern Med. 2008;168(1):80-85.

19. Born-Frontsberg E, Reincke M, Rump LC, et al. Cardiovascular and cerebrovascular comorbidities of hypokalemic and normokalemic primary aldosteronism: results of the German Conn's Registry. J Clin Endocrinol Metab. 2009;94(4):1125-1130.

20. Catena C, Colussi G, Lapenna R, et al. Long-term cardiac effects of adrenalectomy or mineralocorticoid antagonists in patients with primary aldosteronism. Hypertension. 2007;50(5):911-918.

21. Catena C, Colussi G, Di Fabio A, et al. Mineralocorticoid antagonists treatment versus surgery in primary aldosteronism. Horm Metab Res. 2010;42(6):440-445.

22. Vasan RS, Evans JC, Larson MG, et al. Serum aldosterone and the incidence of hypertension in nonhypertensive persons. $N$ Engl J Med. 2004;351(1):33-41.

23. Rossi GP, Bernini G, Caliumi C, et al. A prospective study of the prevalence of primary aldosteronism in 1,125 hypertensive patients. J Am Coll Cardiol. 2006;48(11):2293-2300.

24. Calhoun DA, Nishizaka MK, Zaman MA, Thakkar RB, Weissmann P. Hyperaldosteronism among black and white subjects with resistant hypertension. Hypertension. 2002;40(6):892-896.

25. Pr att-Ubunama MN, Nishizaka MK, Boedefeld RL, Cofield SS, Harding SM, Calhoun DA. Plasma aldosterone is related to severity of obstructive sleep apnea in subjects with resistant hypertension. Chest. 2007;131(2):453-459.

26. Jeunemaitre X, Chatellier G, Kreft-Jais C, et al. Efficacy and tolerance of spironolactone in essential hypertension. Am J Cardiol. 1987;60(10):820-825.

27. Weinberger MH, Roniker B, Krause SL, Weiss RJ. Eplerenone, a selective aldosterone blocker, in mild-to-moderate hypertension. Am J Hypertens. 2002;15(8):709-716.

28. Flack JM, Oparil S, Pratt JH, et al. Efficacy and tolerability of eplerenone and losartan in hypertensive black and white patients. $\mathrm{J}$ Am Coll Cardiol. 2003;41(7):1148-1155.

29. Krum H, Nolly H, Workman D, et al. Efficacy of eplerenone added to renin-angiotensin blockade in hypertensive patients. Hypertension. 2002;40(2):117-123.

30. Sato A, Takane H, Saruta T. High serum level of procollagen type III amino-terminal peptide contributes to the efficacy of spironolactone and angiotensin-converting enzyme inhibitor therapy on left ventricular hypertrophy in essential hypertensive patients. Hypertens Res. 2001;24(2):99-104.

31. Pitt B, Reichek N, Willenbrock R, et al. Effects of eplerenone, enalapril, and eplerenone/enalapril in patients with essential hypertension and left ventricular hypertrophy: the 4E-left ventricular hypertrophy study. Circulation. 2003;108(15):1831-1838.

32. Savoia C, Touyz RM, Amiri F, Schiffrin EL. Selective mineralocorticoid receptor blocker eplerenone reduces resistance artery stiffness in hypertensive patients. Hypertension. 2008;51(2):432-439.

33. Leenen FH, Ruzicka M, Floras JS. Central sympathetic inhibition by mineralocorticoid receptor but not angiotensin II type 1 receptor blockade: are prescribed doses too low? Hypertension. 2012;60(2):278-280.

34. Kontak AC, Wang Z, Arbique D, et al. Reversible sympathetic overactivity in hypertensive patients with primary aldosteronism. $J$ Clin Endocrinol Metab. 2010;95(10):4756-4761.

35. Raheja P, Price A, Wang Z, et al. Spironolactone prevents chlorthalidoneinduced sympathetic activation and insulin resistance in hypertensive patients. Hypertension. 2012;60(2):319-325.

36. Calhoun DA, Jones D, Textor S, et al. Resistant hypertension: diagnosis, evaluation, and treatment: a scientific statement from the American Heart Association Professional Education Committee of the Council for High Blood Pressure Research. Circulation. 2008;117(25):e510-e526.

37. Kumbhani DJ, Steg PG, Cannon CP, et al. Resistant hypertension: a frequent and ominous finding among hypertensive patients with atherothrombosis. Eur Heart J. 2012. 
38. Gallay BJ, Ahmad S, Xu L, Toivola B, Davidson RC. Screening for primary aldosteronism without discontinuing hypertensive medications: plasma aldosterone-renin ratio. Am J Kidney Dis. 2001;37(4):699-705.

39. Strauch B, Zelinka T, Hampf M, Bernhardt R, Widimsky J Jr. Prevalence of primary hyperaldosteronism in moderate to severe hypertension in the Central Europe region. J Hum Hypertens. 2003;17(5):349-352.

40. Eide IK, Torjesen PA, Drolsum A, Babovic A, Lilledahl NP. Low-renin status in therapy-resistant hypertension: a clue to efficient treatment. J Hypertens. 2004;22(11):2217-2226.

41. Gaddam KK, Nishizaka MK, Pratt-Ubunama MN, et al. Characterization of resistant hypertension: association between resistant hypertension, aldosterone, and persistent intravascular volume expansion. Arch Intern Med. 2008;168(11):1159-1164.

42. Gaddam K, Corros C, Pimenta E, et al. Rapid reversal of left ventricular hypertrophy and intracardiac volume overload in patients with resistant hypertension and hyperaldosteronism: a prospective clinical study. Hypertension. 2010;55(5):1137-1142.

43. Nishizaka MK, Zaman MA, Calhoun DA. Efficacy of low-dose spironolactone in subjects with resistant hypertension. Am J Hypertens. 2003;16(11 Pt 1):925-930.

44. Chapman N, Dobson J, Wilson S, et al. Effect of spironolactone on blood pressure in subjects with resistant hypertension. Hypertension. 2007;49(4):839-845.

45. de Souza F, Muxfeldt E, Fiszman R, Salles G. Efficacy of spironolactone therapy in patients with true resistant hypertension. Hypertension. 2010;55(1):147-152.

46. Alvarez-AlvarezB,Abad-Cardiel M, Fernandez-CruzA, Martell-Claros N. Management of resistant arterial hypertension: role of spironolactone versus double blockade of the renin-angiotensin-aldosterone system. J Hypertens. 2010;28(11):2329-2335.

47. Nieto FJ, Young TB, Lind BK, et al. Association of sleep-disordered breathing, sleep apnea, and hypertension in a large community-based study. Sleep Heart Health Study. JAMA. 2000;283(14):1829-1836.

48. Logan AG, Perlikowski SM, Mente A, et al. High prevalence of unrecognized sleep apnoea in drug-resistant hypertension. $J$ Hypertens. 2001;19(12):2271-2277.

49. Gonzaga CC, Gaddam KK, Ahmed MI, et al. Severity of obstructive sleep apnea is related to aldosterone status in subjects with resistant hypertension. J Clin Sleep Med. 2010;6(4):363-368.

50. Gaddam K, Pimenta E, Thomas SJ, et al. Spironolactone reduces severity of obstructive sleep apnoea in patients with resistant hypertension: a preliminary report. J Hum Hypertens. 2010;24(8):532-537.

51. Weber KT. Aldosterone in congestive heart failure. $N$ Engl J Med. 2001;345(23):1689-1697.

52. Pitt B. "Escape" of aldosterone production in patients with left ventricular dysfunction treated with an angiotensin converting enzyme inhibitor: implications for therapy. Cardiovasc Drugs Ther. 1995;9(1):145-149.

53. Jorde UP, Vittorio T, Katz SD, Colombo PC, Latif F, Le Jemtel TH. Elevated plasma aldosterone levels despite complete inhibition of the vascular angiotensin-converting enzyme in chronic heart failure. Circulation. 2002;106(9):1055-1057.

54. Pitt B, Zannad F, Remme WJ, et al. The effect of spironolactone on morbidity and mortality in patients with severe heart failure. Randomized Aldactone Evaluation Study Investigators. $N$ Engl J Med. 1999;341(10):709-717.

55. Zannad F, Alla F, Dousset B, Perez A, Pitt B. Limitation of excessive extracellular matrix turnover may contribute to survival benefit of spironolactone therapy in patients with congestive heart failure: insights from the randomized aldactone evaluation study (RALES). Rales Investigators. Circulation. 2000;102(22):2700-2706.

56. Pitt B, Remme W, Zannad F, et al. Eplerenone, a selective aldosterone blocker, in patients with left ventricular dysfunction after myocardial infarction. N Engl J Med. 2003;348(14):1309-1321.

57. Hayashi M, Tsutamoto $\mathrm{T}$, Wada $\mathrm{A}$, et al. Immediate administration of mineralocorticoid receptor antagonist spironolactone prevents postinfarct left ventricular remodeling associated with suppression of a marker of myocardial collagen synthesis in patients with first anterior acute myocardial infarction. Circulation. 2003;107(20):2559-2565.
58. Zannad F, McMurray JJ, Krum H, et al. Eplerenone in patients with systolic heart failure and mild symptoms. $N$ Engl J Med. January 6, 2011;364(1):11-21.

59. Rogers JK, McMurray JJ, Pocock SJ, et al. Eplerenone in patients with systolic heart failure and mild symptoms: analysis of repeat hospitalizations. Circulation. 2012;126(19):2317-2323.

60. Grandi AM, Imperiale D, Santillo R, et al. Aldosterone antagonist improves diastolic function in essential hypertension. Hypertension. 2002;40(5):647-652.

61. Boccanelli A, Mureddu GF, Cacciatore G, et al. Anti-remodelling effect of canrenone in patients with mild chronic heart failure (AREA IN-CHF study): final results. Eur J Heart Fail. 2009;11(1):68-76.

62. Beygui F, Vicaut E, Ecollan P, et al. Rationale for an early aldosterone blockade in acute myocardial infarction and design of the ALBATROSS trial. Am Heart J. 2010;160(4):642-648.

63. Rossignol P, Menard J, Fay R, Gustafsson F, Pitt B, Zannad F. Eplerenone survival benefits in heart failure patients post-myocardial infarction are independent from its diuretic and potassium-sparing effects. Insights from an EPHESUS (Eplerenone Post-Acute Myocardial Infarction Heart Failure Efficacy and Survival Study) substudy. J Am Coll Cardiol. 2011;58(19):1958-1966.

64. Albert NM, Yancy CW, Liang L, et al. Use of aldosterone antagonists in heart failure. JAMA. 2009;302(15):1658-1665.

65. Samuel JL, Delcayre C. Heart failure: aldosterone antagonists are underused by clinicians. Nat Rev Cardiol. 2010;7(3):125-127.

66. Rassi AN, Cavender MA, Fonarow GC, et al. Temporal trends and predictors in the use of aldosterone antagonists post-acute myocardial infarction. J Am Coll Cardiol. 2012.

67. Fonarow GC, Yancy CW, Hernandez AF, Peterson ED, Spertus JA, Heidenreich PA. Potential impact of optimal implementation of evidencebased heart failure therapies on mortality. Am Heart J. 2011;161(6): 1024-1030. e1023.

68. Fonarow GC, Albert NM, Curtis AB, et al. Improving evidence-based care for heart failure in outpatient cardiology practices: primary results of the Registry to Improve the Use of Evidence-Based Heart Failure Therapies in the Outpatient Setting (IMPROVE HF). Circulation. 2010;122(6):585-596.

69. Mohammed SF, Ohtani T, Korinek J, et al. Mineralocorticoid accelerates transition to heart failure with preserved ejection fraction via "nongenomic effects". Circulation. 2010;122(4):370-378.

70. Mottram PM, Haluska B, Leano R, Cowley D, Stowasser M, Marwick TH. Effect of aldosterone antagonism on myocardial dysfunction in hypertensive patients with diastolic heart failure. Circulation. 2004;110(5):558-565.

71. Mak GJ, Ledwidge MT, Watson CJ, et al. Natural history of markers of collagen turnover in patients with early diastolic dysfunction and impact of eplerenone. J Am Coll Cardiol. 2009;54(18):1674-1682.

72. Edwards NC, Ferro CJ, Kirkwood H, et al. Effect of spironolactone on left ventricular systolic and diastolic function in patients with early stage chronic kidney disease. Am J Cardiol. 2010;106(10):1505-1511.

73. Deswal A, Richardson P, Bozkurt B, Mann DL. Results of the Randomized Aldosterone Antagonism in Heart Failure with Preserved Ejection Fraction trial (RAAM-PEF). J Card Fail. 2011;17(8):634-642.

74. Edelmann FWR, Schmidt AG, et al. Effect of spironolactone on diastolic function and exercise capacity in patients with heart failure with preserved ejection fraction: The Aldo-DHF randomized controlled trial. JAMA. 2013;309(8):781-791.

75. Desai AS, Lewis EF, Li R, et al. Rationale and design of the treatment of preserved cardiac function heart failure with an aldosterone antagonist trial: a randomized, controlled study of spironolactone in patients with symptomatic heart failure and preserved ejection fraction. Am Heart J. 2011;162(6):966-972. e910.

76. SechiLA, Novello M,Lapenna R, etal.Long-term renal outcomes in patients with primary aldosteronism. JAMA. 2006;295(22):2638-2645.

77. Epstein M. Aldosterone blockade: an emerging strategy for abrogating progressive renal disease. Am J Med. 2006;119(11):912-919.

78. Abboud H, Henrich WL. Clinical practice. Stage IV chronic kidney disease. $N$ Engl J Med. 2010;362(1):56-65. 
79. White WB, Duprez D, St Hillaire R, et al. Effects of the selective aldosterone blocker eplerenone versus the calcium antagonist amlodipine in systolic hypertension. Hypertension. 2003;41(5):1021-1026.

80. Furumatsu Y, Nagasawa Y, Tomida K, et al. Effect of renin-angiotensinaldosterone system triple blockade on non-diabetic renal disease: addition of an aldosterone blocker, spironolactone, to combination treatment with an angiotensin-converting enzyme inhibitor and angiotensin II receptor blocker. Hypertens Res. 2008;31(1):59-67.

81. Navaneethan SD, Nigwekar SU, Sehgal AR, Strippoli GF. Aldosterone antagonists for preventing the progression of chronic kidney disease: a systematic review and meta-analysis. Clin JAm Soc Nephrol. 2009;4(3): 542-551.

82. Nielsen SE, Persson F, Frandsen E, et al. Spironolactone diminishes urinary albumin excretion in patients with type 1 diabetes and microalbuminuria: a randomized placebo-controlled crossover study. Diabet Med. 2012;29(8):e184-e190.

83. Edwards NC, Steeds RP, Chue CD, Stewart PM, Ferro CJ, Townend JN. The safety and tolerability of spironolactone in patients with mild to moderate chronic kidney disease. Br J Clin Pharmacol. 2012; 73(3):447-454.

84. Shavit L, Lifschitz MD, Epstein M. Aldosterone blockade and the mineralocorticoid receptor in the management of chronic kidney disease: current concepts and emerging treatment paradigms. Kidney Int. 2012;81(10):955-968.
85. Kolkhof P, Borden SA. Molecular pharmacology of the mineralocorticoid receptor: prospects for novel therapeutics. Mol Cell Endocrinol. 24, 2012;350(2):310-317.

86. Beermann B, Groschinsky-Grind M. Clinical pharmacokinetics of diuretics. Clin Pharmacokinet. 1980;5(3):221-245.

87. Ho PC, Bourne DW, Triggs EJ, Heazlewood V. Pharmacokinetics of canrenone and metabolites after base hydrolysis following single and multiple dose oral administration of spironolactone. Eur J Clin Pharmacol. 1984;27(4):441-446.

88. Overdiek HW, Hermens WA, Merkus FW. New insights into the pharmacokinetics of spironolactone. Clin Pharmacol Ther. 1985;38(4): 469-474.

89. Cook CS, Zhang L, Fischer JS. Absorption and disposition of a selective aldosterone receptor antagonist, eplerenone, in the dog. Pharm Res. 2000;17(11):1426-1431.

90. Cook CS, Berry LM, Bible RH, Hribar JD, Hajdu E, Liu NW. Pharmacokinetics and metabolism of [14C]eplerenone after oral administration to humans. Drug Metab Dispos. 2003;31(11): 1448-1455.
Vascular Health and Risk Management

\section{Publish your work in this journal}

Vascular Health and Risk Management is an international, peerreviewed journal of therapeutics and risk management, focusing on concise rapid reporting of clinical studies on the processes involved in the maintenance of vascular health; the monitoring, prevention and treatment of vascular disease and its sequelae; and the involvement of

\section{Dovepress}

metabolic disorders, particularly diabetes. This journal is indexed on PubMed Central and MedLine. The manuscript management system is completely online and includes a very quick and fair peer-review system, which is all easy to use. Visit http://www.dovepress.com/ testimonials.php to read real quotes from published authors. 